\title{
Lysyl oxidase activity regulates oncogenic stress response and tumorigenesis
}

\author{
C Wiel ${ }^{1,2,3,4}$, A Augert ${ }^{1,2,3,4}$, DF Vincent ${ }^{1,2,3,4}$, D Gitenay ${ }^{1,2,3,4}$, D Vindrieux ${ }^{1,2,3,4}$, B Le Calvé ${ }^{1,2,3,4}$, V Arfi ${ }^{1,2,3,4}$, H Lallet-Daher ${ }^{1,2,3,4}$, \\ C Reynaud $^{4,5}$, I Treilleux ${ }^{3}$, L Bartholin ${ }^{1,2,3,4}$, E Lelievre $^{6,7}$ and D Bernard ${ }^{\star, 1,2,3,4,7}$
}

Cellular senescence, a stable proliferation arrest, is induced in response to various stresses. Oncogenic stress-induced senescence (OIS) results in blocked proliferation and constitutes a fail-safe program counteracting tumorigenesis. The events that enable a tumor in a benign senescent state to escape from OIS and become malignant are largely unknown. We show that lysyl oxidase activity contributes to the decision to maintain senescence. Indeed, in human epithelial cell the constitutive expression of the LOX or LOXL2 protein favored OIS escape, whereas inhibition of lysyl oxidase activity was found to stabilize OIS. The relevance of these in vitro observations is supported by in vivo findings: in a transgenic mouse model of aggressive pancreatic ductal adenocarcinoma (PDAC), increasing lysyl oxidase activity accelerates senescence escape, whereas inhibition of lysyl oxidase activity was found to stabilize senescence, delay tumorigenesis, and increase survival. Mechanistically, we show that lysyl oxidase activity favors the escape of senescence by regulating the focal-adhesion kinase. Altogether, our results demonstrate that lysyl oxidase activity participates in primary tumor growth by directly impacting the senescence stability. Cell Death and Disease (2013) 4, e855; doi:10.1038/cddis.2013.382; published online 10 October 2013

Subject Category: Cancer

Oncogene-induced senescence (OIS) drives cells into a stable cell cycle arrest, causing them to acquire specific markers (morphology, senescence-associated $\beta$-galactosidase activity (SA- $\beta$-Gal), for example) in response to aberrant oncogenic signals. ${ }^{1}$ In responsive cells, the stress generated by oncogene activation counterbalances the proliferationstimulating potential of this activation by triggering senescence. Various benign tumors (melanoma nevi, prostatic intraepithelial neoplasias, lung adenomas) caused by oncogene activation accumulate senescent cells. The tumors remain in a benign state as long as senescence is sustained. Conversion to malignancy of senescing benign lesions thus involves escape from senescence. ${ }^{2-4}$

The $\mathrm{p} 16-\mathrm{Rb}$ and $\mathrm{p} 53$ pathways are key pathways in the regulation of OIS and senescence in general, ${ }^{1,5-8}$ but mounting evidence shows that senescence can occur without any involvement of either of these pathways. To date, little is known about these mechanisms. ${ }^{9-15}$ Most of the data demonstrating a central role of p53, its upstream activators, (DNA damage, p14 ${ }^{\mathrm{ARF}}$ ) and the $\mathrm{p} 16-\mathrm{Rb}$ pathway have been obtained with fibroblasts. Similar data generated in human epithelial cells (HECs) or other lineages are quite rare, and suggest a more complex picture of the genetic events involved in escape from senescence. ${ }^{15}$ Among primary HECs, primary human mammary epithelial cells probably constitute the best-characterized cell model. Post-stasis human mammary epithelial cells are unable to express $\mathrm{p} 16^{\mathrm{INK} 4 a}{ }^{16}$ but they can still enter senescence, in a p53-independent manner in response to oncogenic stress. ${ }^{14}$ We have thus chosen this model to investigate alternative pathways involved in escape from OIS.

Lysyl oxidase activity (LOX), exerted by the LOX, LOXL1, LOXL2, LOXL3, and LOXL4 proteins, ${ }^{17,18}$ regulates cell behavior by oxidizing lysine residues of their substrates and $\mathrm{H}_{2} \mathrm{O}_{2}$ production. LOX-family members are reported to exert both intracellular and extracellular effects, and to share or display specific activities. ${ }^{19-23}$ For example, LOX, LOXL1, and LOXL2 share the ability to promote migration, invasion, and metastasis and to regulate extracellular matrix organization. ${ }^{20,24-30}$ How LOX activity affects cancer cell growth is still a matter of debate, as in some cases it is reported to have no effect ${ }^{24,25}$ and in other cases to favor cancer cell growth $^{19,27,28}$ in vitro or in vivo. Although both LOXL2 and LOXL3 seem to exert some specific effects on cancer by targeting the embryonic transcription factor Snail, ${ }^{22}$ some of the effects shared by LOXL2 and LOX are exerted via activation of the focal-adhesion kinase (FAK). ${ }^{19,24,27,31-33}$

In the context of neu-induced breast tumorigenesis, importantly, LOX activity appears to favor tumorigenesis by regulating $\mathrm{FAK}^{31}$ The oncogenic potential of neu, a tyrosine

\footnotetext{
${ }^{1}$ Inserm U1052, Centre de Recherche en Cancérologie de Lyon; ${ }^{2}$ CNRS UMR5286, Centre de Recherche en Cancérologie de Lyon; ${ }^{3}$ Centre Léon Bérard; ${ }^{4}$ Université de Lyon, Lyon, France; ${ }^{5}$ nserm U1033, Lyon, France and ${ }^{6}$ UMR8161, Institut de Biologie de Lille, CNRS/Universités de Lille 1 et 2, Lille, France

*Corresponding author: D Bernard, Centre de Recherche en Cancérologie de Lyon, 28, rue Laënnec, Centre Léon Bérard, Lyon 69373 , France. Tel: + 33426556792 ; Fax: + 334787827 20; E-mail: david.bernard@ lyon.unicancer.fr

${ }^{7}$ These authors contributed equally to this work.

Keywords: senescence; lysyl oxidase; oncogenic stress; FAK

Abbreviations: 4-OHT, 4-hydroxytamoxifen; BAPN, $\beta$-aminopropionitrile; HEC, human epithelial cells; HEC-TM, HEC-hTert-MEK:ER; HEC-TR, HEC-hTertRAF:ER; FAK, focal-adhesion kinase; LOX, lysyl oxidase; LOXL -1 -2 -3 -4, LOX-Like (-1 -2 -3 -4); OIS, oncogene-induced senescence; PDAC, pancreatic ductal adenocarcinoma; SA- $\beta$-Gal, senescence-associated $\beta$-galactosidase; WT, wild-type mice; KIA, Pdx1-Cre, LSL-KrasG12D/ +, INK4a/Arflox/lox mice

Received 31.7.13; revised 03.9.13; accepted 03.9.13; Edited by A Finazzi-Agró
} 
kinase receptor, can be limited by activation of the OIS fail-safe program. ${ }^{34}$ We thus hypothesized that LOX activity might affect oncogene-induced tumorigenesis by impacting the OIS fail-safe program triggered by oncogenic activation. We show that LOX activity is indeed a key regulator of OIS, thereby affecting tumorigenesis.

\section{Results}

An unstable OIS model based on HECs. To study OIS in HECs, we used post-stasis mammary HECs, which do not express $\mathrm{p} 16^{\mathrm{INK} 4 a} .{ }^{16}$ We reasoned that this extinction of p16 ${ }^{\text {INK4a }}$ would favor senescence instability, as demonstrated by other studies. ${ }^{35,36}$ The cells were next immortalized by forced hTert expression (sustaining telomere integrity and thus avoiding replicative senescence ${ }^{16}$ ) and stably infected to express an inducible oncogene: MEK:ER (HEC-TM cells) or, in some experiments, RAF:ER (HEC-TR cells). In HEC-TM cells, where MEK was activated by a 3-day treatment with 4-hydroxytamoxifen (4-OHT) (Figure 1a), as indicated by increased phosphorylation of its substrate ERK (Figure 1b), we first checked that OIS was induced on d0. OIS induction by 4-OHT was demonstrated by loss of the two proliferation markers examined (cyclin A, a cyclin accumulated in the $S$ to early $M$ phases and PhosphoH3Ser10, a marker of late mitosis) (Figure 1b), growth arrest (Figure 1c), the appearance of the SA- $\beta$-Gal marker (Figure 1d) and an increase of the senescence markers IL $8^{5}$ and Sprouty $2^{37}$ (Figure 1e). As hypothesized, HEC-TM cells monitored after entry into senescence proved able to resume growth (Figure 1c) and to lose SA- $\beta$-Gal activity (Figure 1d) and other senescence markers (Figure 1e). This model is thus a suitable model for uncovering new mechanisms accelerating or inhibiting escape from OIS in HECs.

\section{LOX activity regulates escape from OIS in HECs.}

To investigate the possible role of LOX activity in regulating senescence, we first used RT-qPCR to measure levels of transcripts corresponding to Lox-family proteins in HECs. LOX, LOXL1, and LOXL2 mRNAs were detected in these cells but LOXL3 and LOXL4 transcripts were not (Supplementary Figure 1). Cells were then infected with LOX- or LOXL2-encoding vectors, two main LOX-family members expressed in HEC, and their expression was checked by immunoblotting (Figure 2a). Cells constitutively expressing LOX, LOXL2, or neither of these were treated with 4-OHT to trigger senescence (d0), released from oncogenic stress for 3 days (d3), and then examined for escape from senescence (Figure 1a). On d3, although the initial growth arrest (d0) was similar in control, LOX-expressing, and LOXL2-expressing cells (Figure 2b), the LOX- and LOXL2expressing cells displayed escape from OIS in contrast to control cells, that is, they were growing (Figure $2 b$ ), fewer of them were SA- $\beta$-Gal-positive (Figure 2c), and they displayed a decrease of senescence markers (Figure $2 d$ ). Thus, LOX and LOXL2 promote escape from OIS and this effect is not due to a simple growth advantage, as their constitutive expression does not affect cell growth in the absence of oncogenic stress induction (Figure 2e).
Secreted LOX favors escape from OIS in HECs. As LOX proteins are secreted, their production by various cells of the tumor microenvironment (such as fibroblasts or endothelial cells) might contribute, along with synthesis by the epithelial cells, to affecting the response to oncogenic stress. We thus examined whether extracellular LOX might impact OIS. We first measured LOX protein levels in the supernatants of constitutively expressing cells. As expected, LOX and LOXL2 were found in the supernatants (Figure 3a), LOX in its $30-\mathrm{kD}$ mature form lacking the pro-domain and LOXL2 displaying the same size as in the lysate, as this protein contains no pro-domain. ${ }^{17,18}$ Accordingly, the LOX and LOXL2 supernatants displayed increased LOX activity (Figure $3 b$ ). The results of colony assays (Figure $3 c$ ) and SA- $\beta$-Gal staining (Figure $3 d$ ) showed that adding LOX or LOXL2 supernatant to HEC-TM cells is sufficient to trigger escape from senescence. Importantly, LOX catalytic activity was found to be responsible for LOX-triggered escape from senescence: this escape was completely blocked upon addition of 3-aminopropionitrile (BAPN), an inhibitor of the catalytic activity of all the LOX proteins ${ }^{38-40}$ (Figures $3 \mathrm{c}$ and d), and a catalytically inactive LOX form proved unable to induce senescence reversal (Supplementary Figure 2).

Inhibiting LOX catalytic activity stabilizes OIS in HECs. Interestingly, HEC-TM cells displayed spontaneous escape from senescence after oncogenic stress and OIS induction (Figures 1 and $4 a-b$ ). As increasing LOX activity favors senescence escape, we next investigated whether this spontaneous escape might be inhibited by inhibiting any endogenous LOX activity due to LOX, LOXL1, and/or LOXL2 (Supplementary Figure 1). During oncogenic stress, LOX activity inhibition by BAPN treatment did not significantly affect entry into OIS (Figures $4 b-d$ ), but it did, strikingly, completely block spontaneous escape from OIS, as shown by (i) the inability of treated cells to grow, in contrast to control cells (Figure $4 \mathrm{~b}$ ), (ii) their ability to maintain SA- $\beta$-Gal activity (Figure 4c) and other senescence markers (Figure 4d) under conditions where untreated cells lost these markers. These effects were not due to direct inhibition of cell growth by LOX, as BAPN treatment alone did not modify HEC-TM cell growth (Figure $4 \mathrm{e}$ ). This set of data was obtained by inhibiting LOX activity during oncogenic stress induction. Interestingly, inhibiting LOX activity when the cells were already senescent (d0) also stabilized senescence (Supplementary Figure 3), supporting the idea that LOX activity modifies escape from senescence but not entry into senescence.

LOX activity regulates OIS stability in vivo. To address the relevance of these interesting in vitro observations on HECs, we sought an appropriate mouse model that would be relevant to human cancer biology. We decided to focus on pancreatic ductal adenocarcinoma (PDAC), because (i) p16 is generally lost in human PDAC, ${ }^{41}$ and (ii) we observed LOX and LOXL2 induction (Supplementary Figure 4a) as well as some senescence (Supplementary Figure $4 b$ ) in a mouse model developing aggressive PDAC at the frequency of $100 \%$ by the age of $6-7$ weeks as a result of pancreatic expression of an oncogenic Ras in a p16-null background 
a
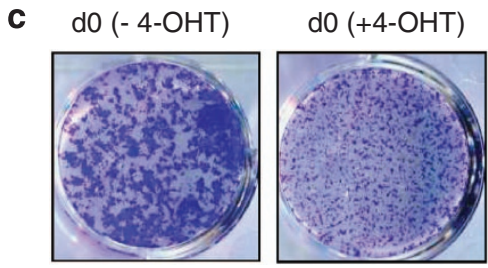

d

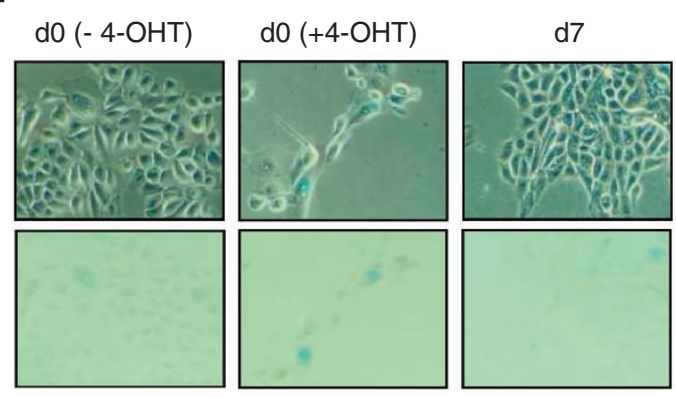

b

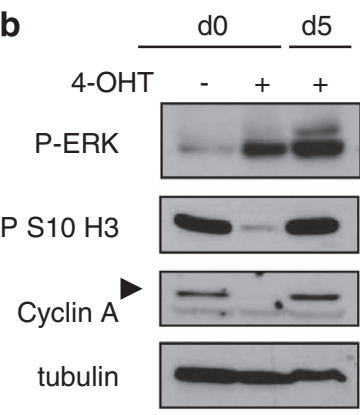

d7

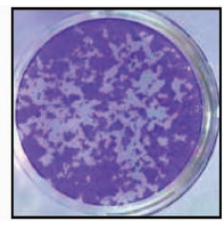

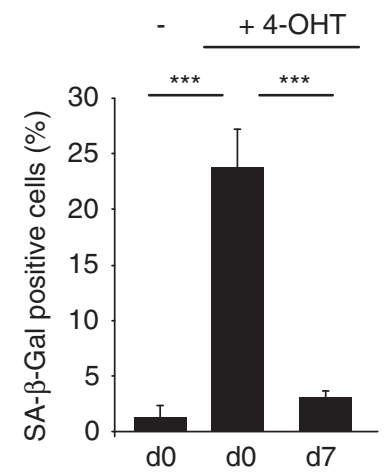
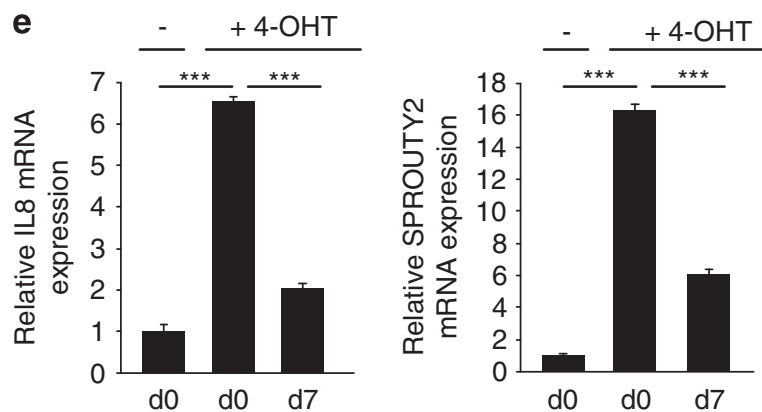

Figure 1 HEC-TM cells enter senescence after MEK activation. (a) HEC-TM cells were treated for 3 days with 4-OHT to activate MEK and were monitored the following days. (b) Cell extracts were prepared and analyzed by immunoblotting with the indicated antibodies at d0 or at d5. Tubulin was used as a loading control. (c) Cells were PFAfixed and crystal violet-stained. (d) Cells were fixed and assayed for SA- $\beta$-Gal activity. (e) RNAs were prepared and RT-qPCRs were performed against the indicated genes. Expression was normalized against the level of actin mRNA. The experiments shown in this figure are representative of at least 3 independent experiments

(Pdx1-Cre, LSL-Kras ${ }^{\mathrm{G} 12 \mathrm{D} /+}$, INK4a/Arf $\left.{ }^{\mathrm{lox} / \mathrm{lox} 42,43}\right)$. Wild-type (WT) and Pdx1-Cre, LSL-Kras ${ }^{\mathrm{G} 12 \mathrm{D} /+}$, INK4a/Arf ${ }^{\text {lox/lox }}(\mathrm{KIA})$ mice were killed 45 days after birth. The pancreases of KIA and WT animals were dissected and the normal zone was separated from the tumoral zone. In the KIA mice, the normal part (confirmed by hematoxylin-phloxine-saffron (HPS) staining) showed senescence (as indicated by the presence of SA- $\beta$-Gal activity) and tested negative for the proliferation marker Ki67 (Supplementary Figure 4b). In contrast, the tumoral part (confirmed by HPS staining) no longer displayed any SA- $\beta$-Gal activity and was Ki67-positive (Supplementary
Figure $4 b)$. The pancreases of WT animals displayed no SA- $\beta$-Gal activity and no Ki67 staining (Supplementary Figure $4 b$ ). KIA mice thus constitute an attractive model for testing OIS stability, and more specifically, the ability of LOX activity to regulate OIS in vivo.

To examine whether increased LOX activity might accelerate senescence, we first injected concentrated LOX protein supernatants (Figure 3) in mice. The LOX activity increase was observed in pancreatic extract for at least $4 \mathrm{~h}$ after intraperitoneal injection (Supplementary Figure 5). We then injected LOX protein supernatants into KIA mice, every day 
a

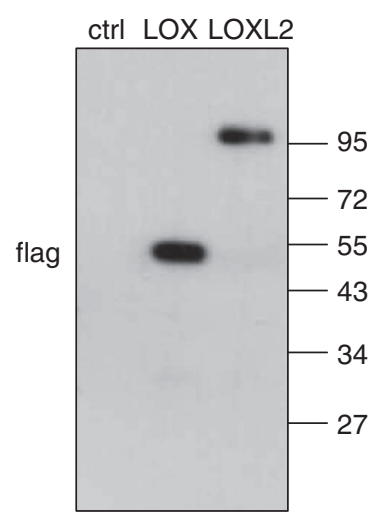

b

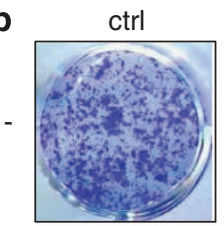

do

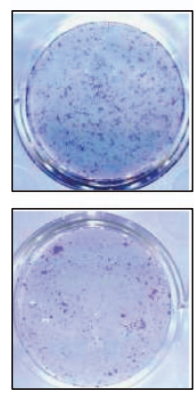

LOX
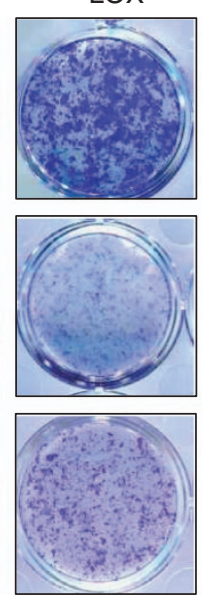

LOXL2
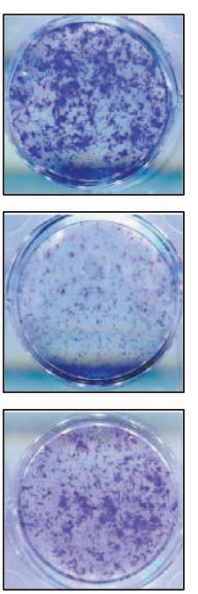

c
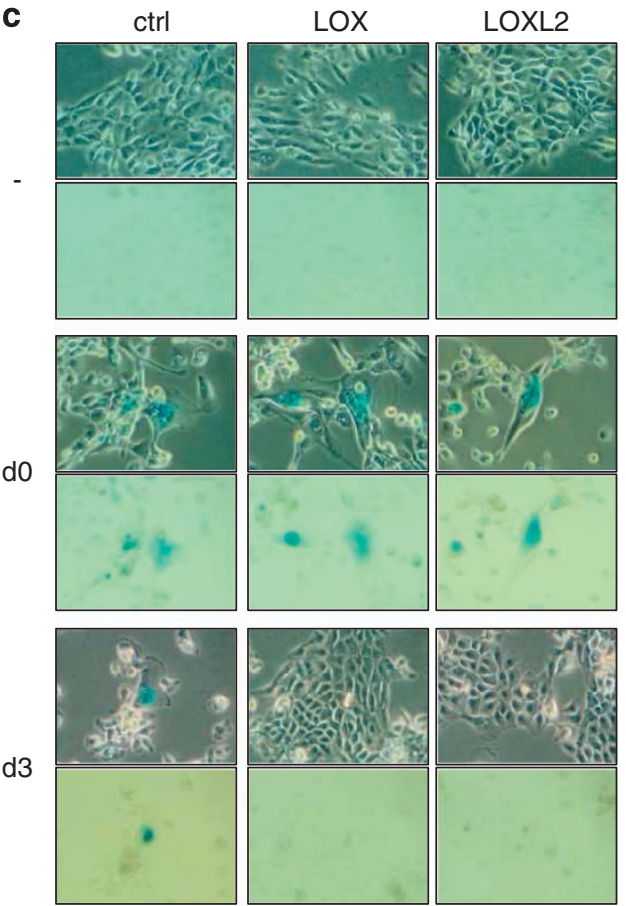

e

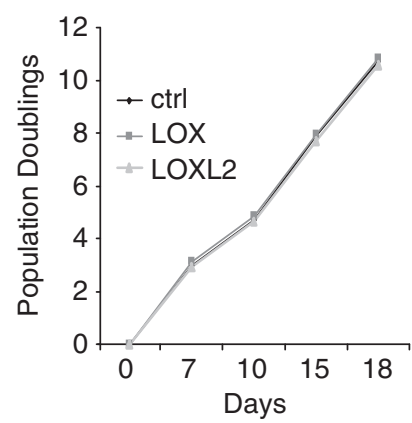

LOXL2

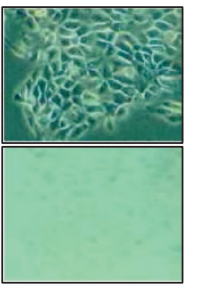

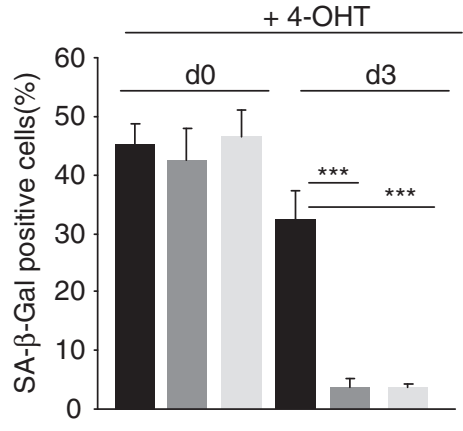
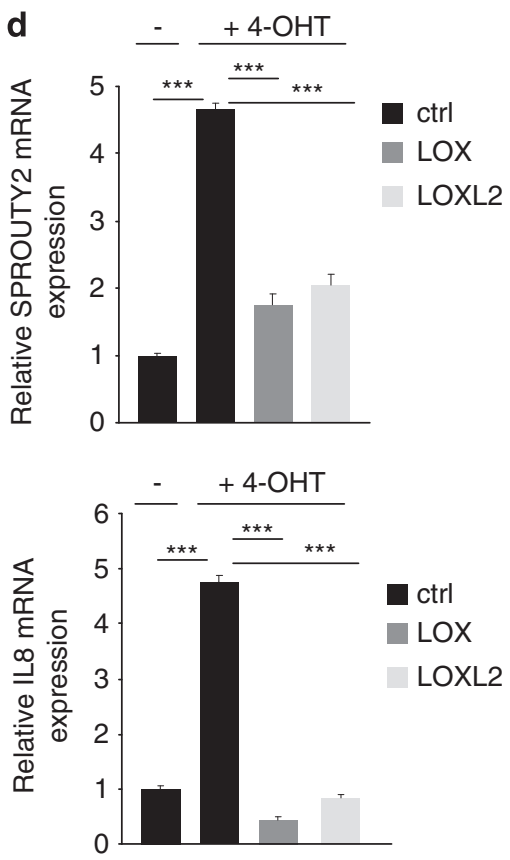

Figure 2 LOX expression and LOXL2 expression favor escape from OIS. HEC-TM cells were infected with an empty control or a LOX- or LOXL2-encoding vector and puromycin selected. (a) Cell lysates were prepared and analyzed by immunobloting with an anti-flag antibody. (b) HEC-TM cells were treated or not for 3 days with 4-OHT (d0), PFA-fixed and crystal violet-stained to measure cell growth at the indicated time points. (c) Cells were treated as in (b), fixed, and assayed for SA- $\beta$-Gal activity. (d) RNAs were prepared at d3 and RT-qPCRs were performed against the indicated senescence markers. Expression was normalized against the level of actin mRNA. (e) HEC-TM cells expressing a LOX-encoding, a LOXL-encoding or an empty control vector were counted after each passage and seeded at the same density. Population doublings are presented. The experiments shown in this figure are representative of at least three independent experiments 
a

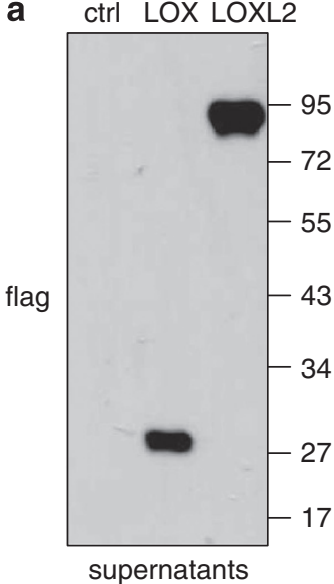

b

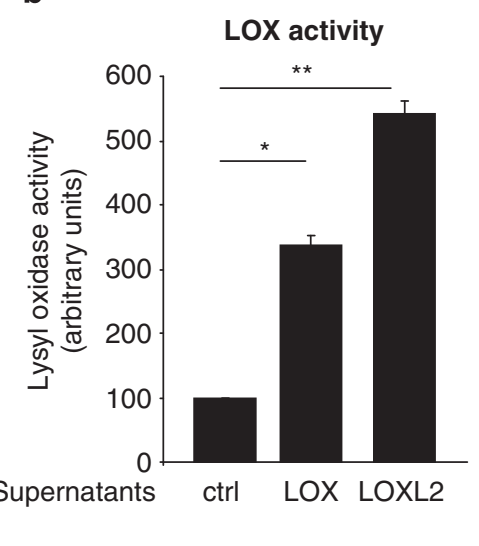

C
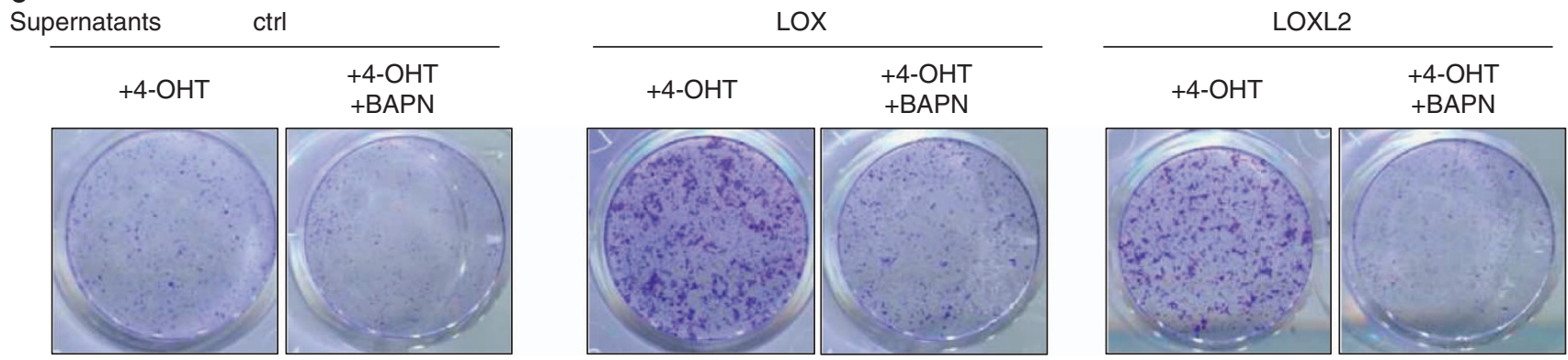

d
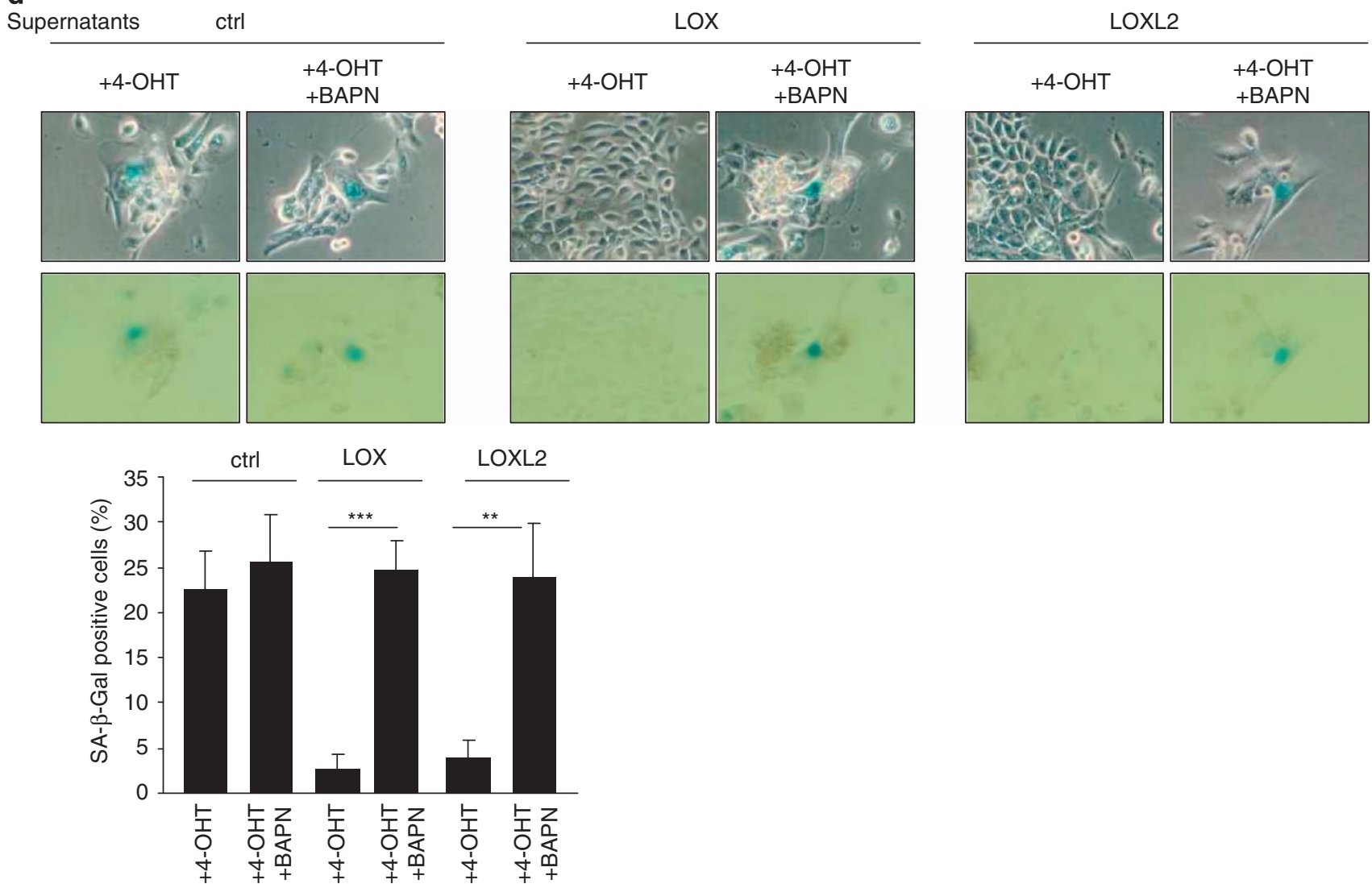
from days 23 to 38 after birth, and confirmed the LOX activity increase on the basis of better collagen fiber organization in the pancreatic tumor microenvironment 39 days after birth (Figure 5a). The SA- $\beta$-Gal (Figure 5b), Dec1 (Figure 5c) and Wnt16B (Figure $5 d$ ) senescence markers were all found to be lower and the Ki67 proliferation marker higher (Figure 5e) in mice injected with LOX supernatants than in mice injected with control supernatants. Hence, in agreement with the in vitro results, LOX activity can also accelerate escape from senescence in vivo in an aggressive model of PDAC.

We next examined whether LOX activity inhibition by BAPN might prevent the spontaneous escape from senescence observed 45 days after birth. The pancreases of BAPNtreated WT animals displayed no SA- $\beta$-Gal activity and no Ki67 staining (Supplementary Figure 4b), in agreement with the in vitro observation that BAPN cannot induce senescence in the absence of oncogenic stress (Figure 4e). BAPN injection into KIA mice resulted in the inhibition of pancreatic LOX catalytic activity, as measured by collagen fiber organization (Figure 6a). The pancreases of untreated mice were found to be SA- $\beta$-Gal-negative, whereas those of the BAPN-treated mice were SA- $\beta$-Gal-positive (Figure $6 \mathrm{~b}$ ) and displayed increased levels of the Dec1 and Wnt16B senescence markers (Figures $6 c$ and $d$ ) and a decreased level of the Ki67 proliferation marker (Figure 6e). Importantly, LOX-inhibition-induced stabilization of senescence led to a significant increase in mouse survival (Figure 6f). Altogether, these results tally with our in vitro results and strongly support an involvement of LOX in regulating senescence stability, in vivo tumorigenesis, and survival.

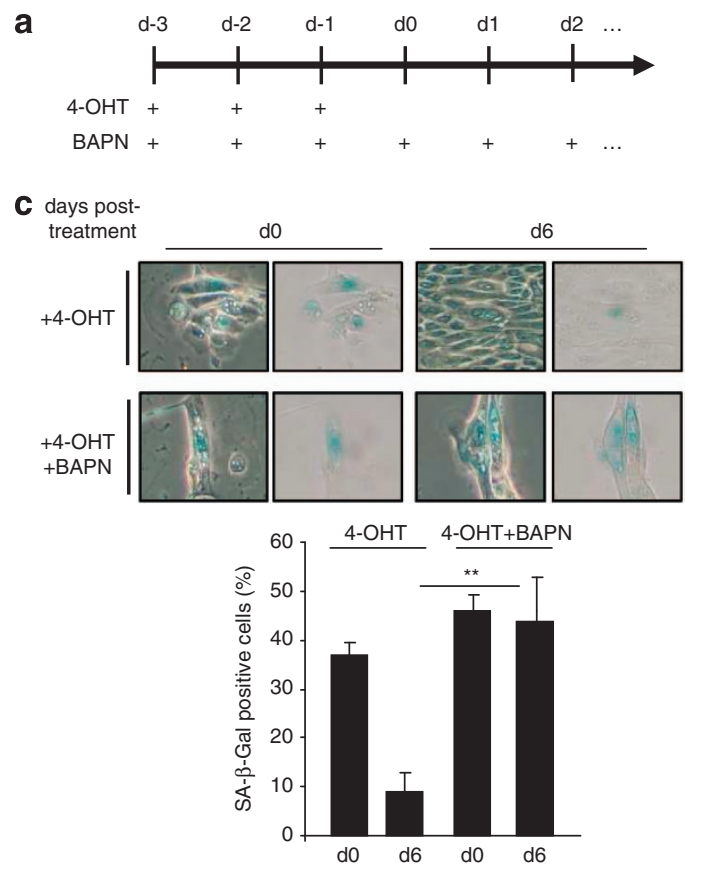

\section{b}
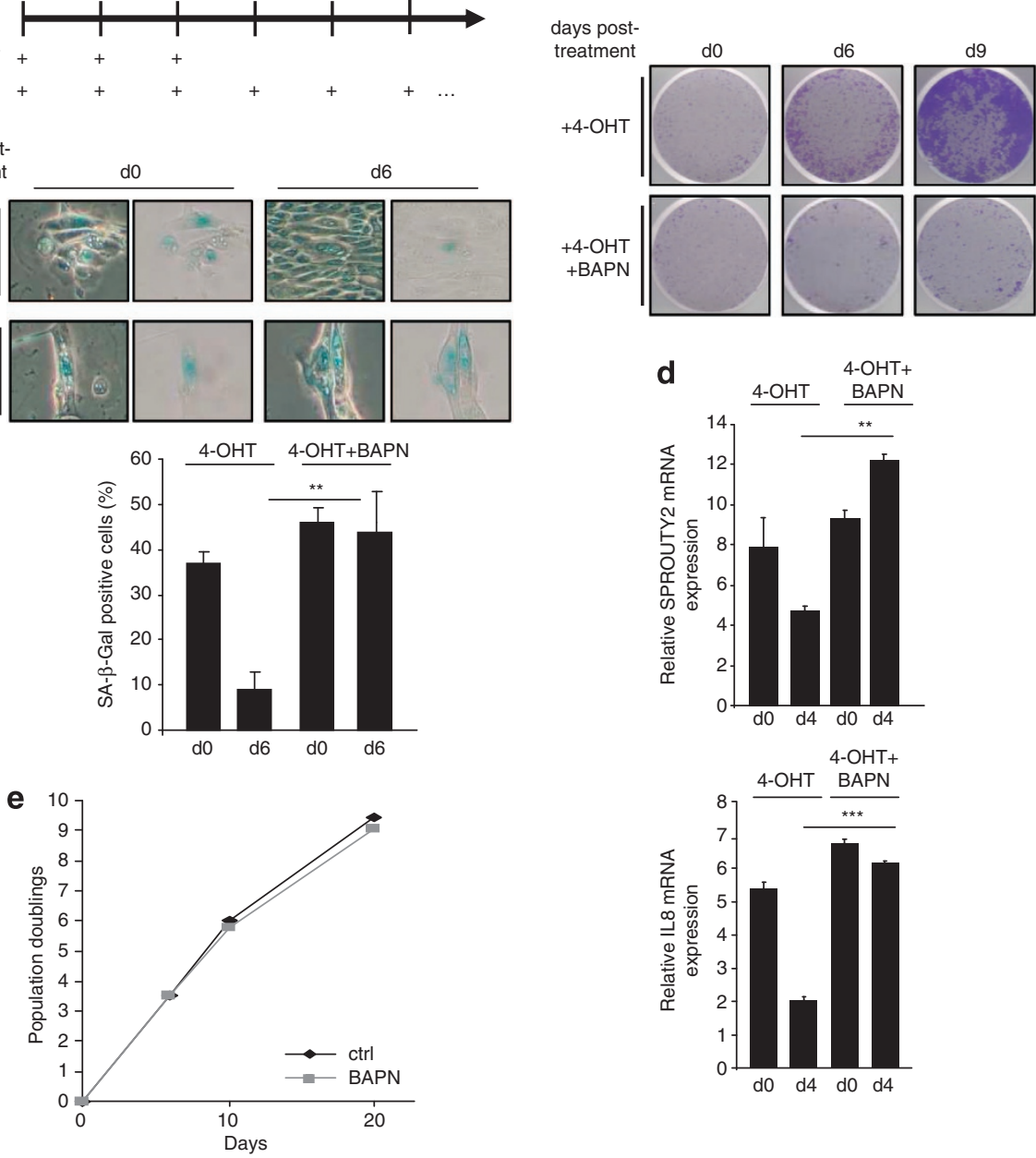

Figure 4 LOX activity inhibition blocks spontaneous escape from OIS. (a) Protocol of treatment to induce senescence and inhibition of its reversal in HEC-TM cells. (b) HEC-TM cells were treated for 3 days with 4-OHT, with or without BAPN. Cells were PFA-fixed and crystal violet-stained to measure cell growth at various time points. (c) Cells were treated as in (b), fixed and assayed for SA- $\beta$-Gal activity or (d) RNA were prepared and analyzed by RT-qPCR against the indicated genes and normalized with respect to actin. (e) HEC-TM cells were treated or not with BAPN every day. After each passage, cells were counted and seeded at the same density. Population doublings are presented. The experiments shown in this figure are representative of at least three independent experiments

Figure 3 Activity of secreted LOX or LOXL2 favors escape from OIS. (a) Supernatants of LOX- or LOXL2-expressing HEC-TM cells or of ones containing the empty control vector were concentrated and analyzed by immunoblotting with an anti-flag antibody. (b) LOX activity was measured in concentrated supernatants and normalized to $100 \%$ for the ctrl cells $( \pm$ S.E.M.). (c) HEC-TM cells were treated for 3 days with 4-OHT + I - BAPN together with the indicated supernatant, PFA-fixed and crystal violet-stained to measure cell growth on $\mathrm{d} 3$, and (d) assayed for $\mathrm{SA}-\beta$-Gal activity on $\mathrm{d} 3$. The experiments shown in this figure are representative of at least three independent experiments 
a

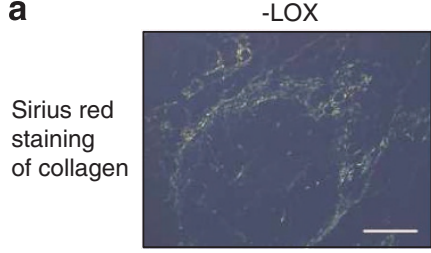

b

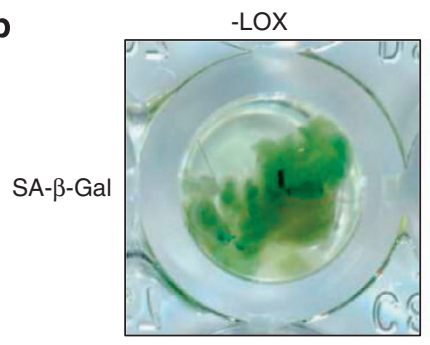

C

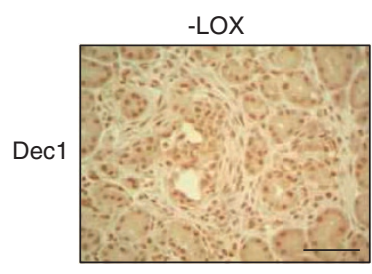

d

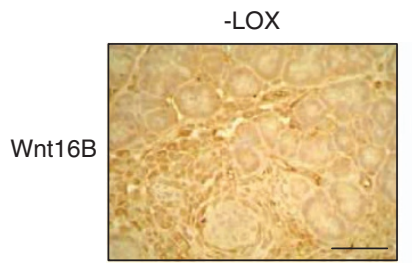

e

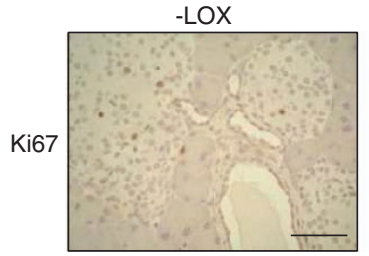

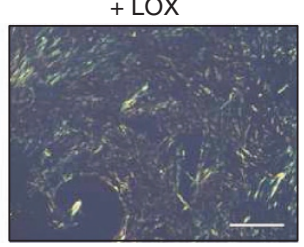

+ LOX

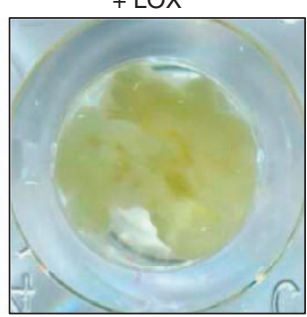

+ LOX
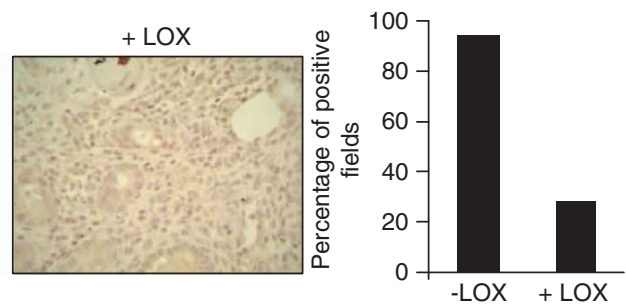

+ LOX
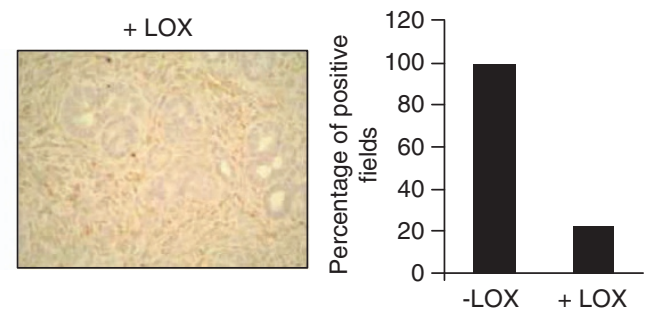

+ LOX
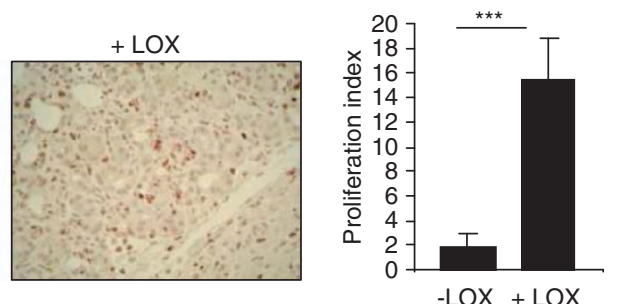

Figure 5 LOX activity favors escape from senescence in vivo in a model of PDAC. Pdx1-Cre;LSL-Kras ${ }^{\mathrm{G} 12 \mathrm{D} /+}$; Ink4a/Arf ${ }^{\text {lox/lox }}$ (KIA) mice were injected with concentrated LOX or control supernatant every day from day 23 after birth. Mice were killed 39 days after birth and their pancreases fixed before analysis. (a) A Sirius red staining of collagen was performed at the indicated times. Collagen fiber organization is illustrated by pictures made by polarized light microscopy (scale bar: $200 \mu \mathrm{m}$ ). (b) SA- $\beta$-Gal assays were performed on pancreas samples at the indicated times. (c) IHC performed against the Dec1 senescence marker. (d) IHC against the Wnt16B senescence marker. (e) IHC against the Ki67 proliferation marker. For (c-e) Scale bar: $50 \mu \mathrm{m}$

LOX activity impacts OIS by modulating FAK activity. LOX activity is reported in various contexts to impact FAK activity. ${ }^{19,24,27,31-33}$ We thus investigated in vitro and in vivo whether FAK might have a role in regulating senescence. In vitro, the level of P-FAK (FAK $\left.{ }^{\mathrm{Y} 397}\right)$ was found to decrease during OIS (Figure 7a), and this decrease was sustained by LOX activity inhibition (Figure 7b). In vivo, the level of P-FAK was found to increase in the pancreases of LOX-injected KIA mice (Figure 7c) and to decrease in those of KIA mice when LOX activity was inhibited by BAPN treatment (Figure 7d).
That FAK signaling affects OIS stability is further supported by the observation that sub-cytostatic doses of two FAK inhibitors (FAK Inhibitor 14 and PF 573228) inhibited growth resumption (Figure $8 \mathrm{a}$ ) and sustained senescence markers (Figures $8 \mathrm{~b}$ and $\mathrm{c}$ ). To determine whether FAK activation might allow cells to escape from 4-OHT/BAPN-induced irreversible senescence, we used HEC-TR cells expressing a constitutively active form of FAK (Figure 8d). After 4-OHT/ BAPN treatment, the ability of these cells to form colonies (Figure 8e) and their decreased levels of senescence markers 
a

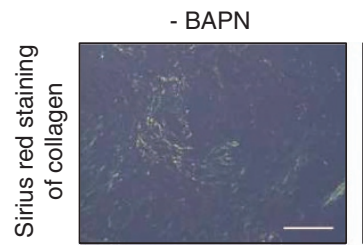

c
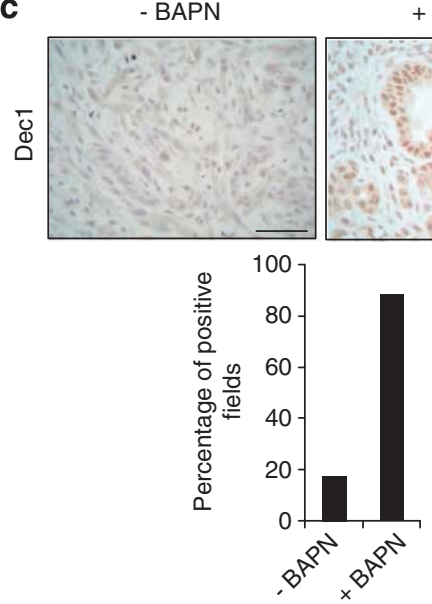

e

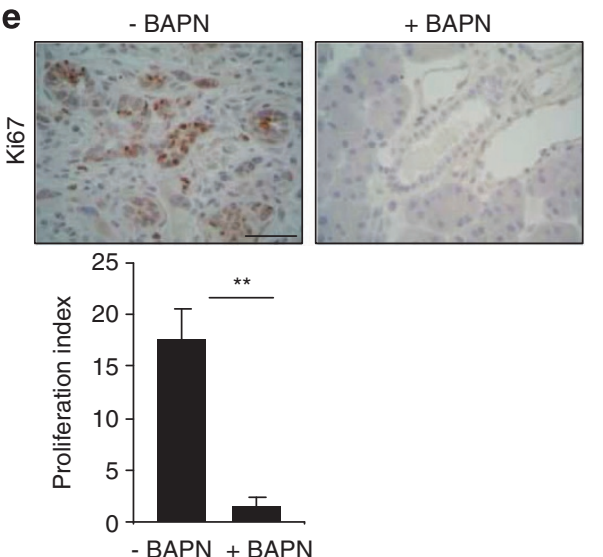

+ BAPN

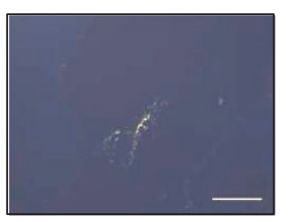

b
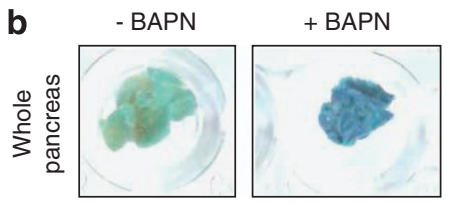

- BAPN
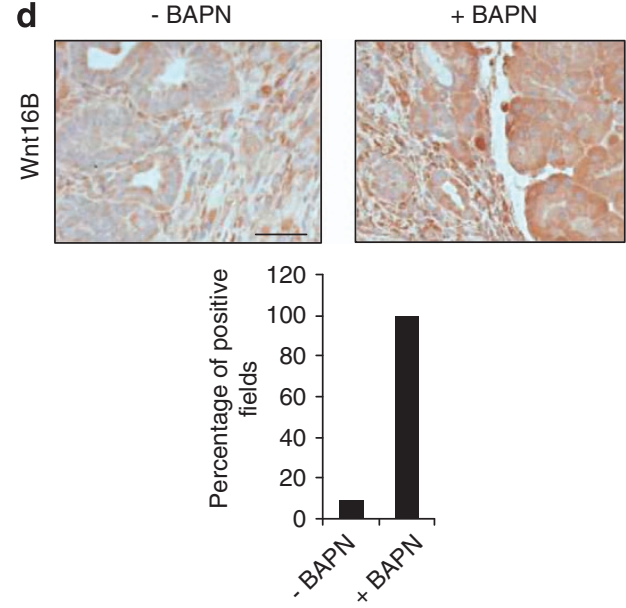

f

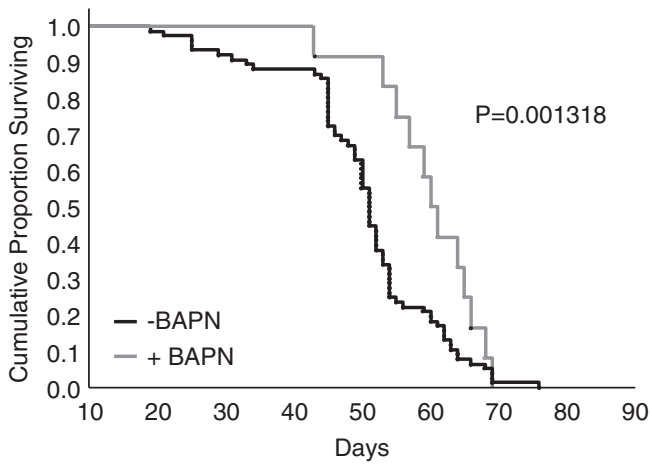

Figure 6 LOX inhibition stabilizes senescence and delays carcinogenesis in vivo. Pdx1-Cre;LSL-Kras ${ }^{\text {G12D/+ }}$;Ink4a/Arflox/lox (KIA) mice were injected or not with BAPN, three times a week from day 25 after birth. Mice were killed 45 days after birth and their pancreases fixed before analysis. (a) Sirius red staining of collagen was performed and representative photographs obtained by polarized light microscopy are displayed (scale bar: $200 \mu \mathrm{m}$ ). (b) SA- $\beta$-Gal assays were performed on pancreas samples at the indicated times. (c) IHC against the Dec1 senescence marker. (d) IHC against the Wnt16B senescence marker. (e) IHC against the Ki67 proliferation marker. For (c-e) scale bar: $50 \mu \mathrm{m}$. (f) KIA mice were injected $(n=12)$ or not $(n=75)$ with the LOX inhibitor BAPN. Kaplan-Meier analyses of the probability to survive were performed. $P$-values were calculated using a log rank test

(Figures $8 f$ and $g$ ) showed that they could escape from treatment-induced irreversible senescence even when LOX activity was inhibited. These data constitute compelling evidence that LOX activity influences OIS by regulating FAK signaling.

\section{Discussion}

Little is known about pathways, other than the p16-Rb and the p53 pathways, that might participate in controlling OIS. Here we show that LOX activity has a role in regulating escape from OIS, as this escape is triggered when LOX activity is increased by constitutive LOX or LOXL2 expression or by treating cells with secreted LOX or LOXL2.

Interestingly, HEC-TM cells show spontaneous escape from OIS. This instability of senescence might be due to loss of $\mathrm{p} 16^{1 \mathrm{NK} 4 \mathrm{a}}$ resulting from methylation of its promoter, ${ }^{16}$ as a decreased $p 16$ level is reported to possibly favor escape from senescence. $^{35,36}$ This raises the question of whether the phenomenon we observed is really senescence. We think it is, because (i) the level of SA- $\beta$-Gal senescence marker increases, (ii) the levels of other independent senescence markers increase, and (iii) proliferation is blocked as long as the oncogenic stress is sustained. Interestingly, blocking LOX activity in this situation is sufficient to stabilize the growth 

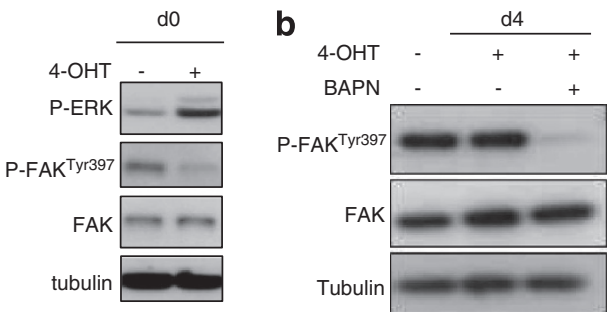

C
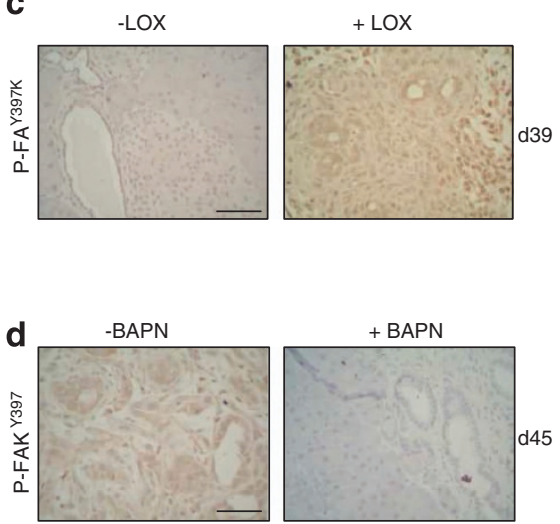
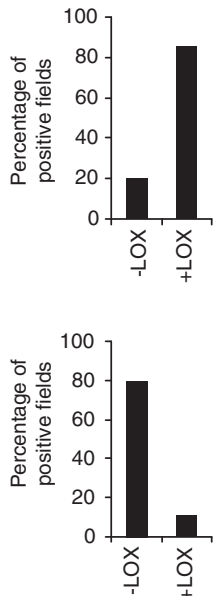

Figure 7 FAK is modulated by LOX activity. (a) HEC-TM wells were treated for 3 days with 4-OHT. Cell extracts were prepared and analyzed by immunoblotting with antibodies directed against P-ERK, P-FAK, FAK, and tubulin. (b) HEC-TM cells were treated for 3 days with 4-OHT, with or without BAPN. BAPN treatment was carried out for 4 days. Cell extracts were prepared and analyzed by immunoblotting with antibodies directed against P-FAK, FAK, and tubulin. (c) Pancreases of mice, 39 days after birth, treated or not with LOX supernatants, were analyzed by $\mathrm{HC}$ with an antibody targeting P-FAK. (d) Pancreases of mice, 45 days after birth, treated or not with BAPN, were analyzed by $\mathrm{IHC}$ with an antibody targeting P-FAK

arrest and the senescence markers and thus to maintain the senescent phenotype. Importantly, raising or lowering the LOX activity does not affect the proliferation of HEC cells. The growth-promoting effect of LOX activity is observed only in the context of OIS. In our in vivo model we have also observed a transient senescent phenotype, possibly due to the lack of $p 16^{\text {INK4a }}$ expression, and again this phenotype is regulated by LOX activity.

LOX and LOXL2 are reported to be expressed both by epithelial cells and by cells of the tumor microenvironment. $^{20,31,44}$ This means that these proteins, although expressed by different cells of different lineages, might impact epithelial cell behavior. To recapitulate the production of LOX and LOXL2 by tumor cells as well as cells of the tumor microenvironment, we have manipulated extracellular LOX and LOXL2 and described their impact on the epithelial cells response to the oncogenic stress.

Like other groups in the context of metastasis, primary tumor growth, or tumorigenesis, we observe an influence of FAK on biological responses to LOX activity. ${ }^{19,24,27,31-33}$ We might speculate that the PI3K pathway is a downstream effector of the action of FAK on senescence, as it is known to be regulated by $\mathrm{FAK}^{45}$ and as it has recently been reported to inhibit senescence induction by activated RAS or RAF in mouse models of melanoma or pancreatic cancer. ${ }^{46,47}$

How LOX activity activates FAK remains unclear. Some suggest that activation might be due to ECM stiffening, while others propose that it might be due to the hydrogen peroxide released by intrinsic LOX activity. ${ }^{19,24,27,31-33}$

Altogether, our results support the view that the LOX activity, in addition to the p16 $16^{\text {INK } 4 a}$ pathway, regulates OIS and might thus affect tumorigenesis.

\section{Materials and Methods}

Cell culture. Mammary HECs (Lonza, Barcelona, Spain) were cultured in MEBM (Promocell, Heidelberg, Germany) and penicillin/streptomycin (Life Technologies, Saint Aubin, France). Virus-producing GP293 cells (Clontech, Saint-Germain-en-Laye, France) were cultured in DMEM (Life Technologies) supplemented with 10\% FBS (Thermo Fisher Scientific, Waltham, MA, USA) and penicillin/streptomycin. Infected cells were selected, as appropriate, with neomycin $(100 \mu \mathrm{g} / \mathrm{ml})$, puromycin $(500 \mathrm{ng} / \mathrm{ml})$, or both.

Reagents and plasmids. Four-hydroxytamoxifen (4-OHT) (Sigma, Lyon, France) was used daily for 3 days at $250 \mathrm{~nm}$ final concentration. 3Aminopropionitrile (fumarate salt) (A3134, Sigma) was used daily at $350 \mu \mathrm{m}$ final concentration for in vitro analysis. FAK inhibitor 14 (3414, Tocris Bioscience, Bristol, UK) and PF 573228 (3239, Tocris Bioscience) were used daily at the following respective final concentrations: $250 \mathrm{~nm}$ and $500 \mathrm{~nm}$.

The following plasmids were used: pWZL-Neo-Myr-Flag-FAK (Addgene plasmid 20610, Cambridge, MA, USA), ${ }^{48}$ pBabe-hygro-hTert (Addgene plasmid 1773), ${ }^{49}$ pBAbe-puro-Raf:ER, ${ }^{50}$ pNLP-Neo-Mek:ER. ${ }^{3}$ For LOX and LOXL2 cloning, the C-terminally FLAG-tagged mouse LOX and LOXL2 cassettes were amplified by PCR with PFU (Agilent Technologies, Les Ulis, France) ${ }^{44}$ and introduced into the pLPCX vector (Clontech) between the Notl and Clal sites. Catalytically inactive LOX was created by PCR site-directed mutagenesis to introduce the inactive mutations $\mathrm{K} 314 \mathrm{~A}$ and $\mathrm{Y} 349 \mathrm{~F}$, as previously described ${ }^{51}$ and cloned into $\mathrm{pLPCX}$ vector as indicated above.

Transfection and infection. GP293 cells were transfected with PEI reagent according to the manufacturer's recommendations (Euromedex, Souffelweyersheim, France). Two days after transfection, target HECs were infected with viral supernatant mixed with fresh medium (1/2) and polybrene (final concentration: $8 \mu \mathrm{g} / \mathrm{ml}$ ).

Antibodies. The antibodies used were: anti-phosphoERK (9101, Cell Signaling, Danvers, MA, USA), anti-phosphoFAKTyr397 (3283, Cell Signaling, 44624G, Life Technologies), anti-FAK (3285, Cell Signaling), anti-flag (200472, Agilent Technologies), anti-phosphohistone3Ser10 (ab14955, Abcam, Paris, France), anti-cyclinA (H432, sc-751, Santa Cruz Biotechnology, Heidelberg, Germany), anti-Ki67 (clone Tec-3, M7249, DAKO, Les Ulis, France), and anti-tubulin (T6199, Sigma), WNT16B (LS-A9630, MBL, Nanterre, France).

Cell growth assays. Fifteen thousand cells were seeded into six-well plates and treated or not with the indicated compound(s). At the end of the experiments, cells were fixed with $4 \%$ PFA for 15 min, washed with water, and stained with a crystal violet solution (Sigma).

LOX activity assays. Activity assays for detection of BAPN-inhibitable LOX enzyme activity were performed with the Amplex Red Monoamine Oxidase Assay Kit (A12214, Molecular Probes, Life Technologies, Saint Aubin, France). Briefly, conditioned cell medium was concentrated with Amicon 10-kDa cutoff filters (Millipore, Darmstadt, Germany). Aliquots were added to the final reaction mix containing $100 \mu \mathrm{M}$ Amplex Red, $0.5 \mathrm{U} / \mathrm{ml}$ horseradish peroxidase, $2 \mathrm{mM}$ benzylamine substrate and incubated for $1 \mathrm{~h}$. The fluorescent product was excited at $560 \mathrm{~nm}$ and the emission was read at $590 \mathrm{~nm}$. Parallel assays were prepared with $500 \mu \mathrm{m}$ BAPN to completely inhibit the activity of LOX, and the difference in emission intensity was recorded. Assays were run in quintuplicate and specific activity is reported as a mean of all assays.

RT-qPCR. Cells were lysed in TriReagent (Sigma) and total RNAs were isolated via an acidphenol extraction procedure using Phase Lock gel tubes $\left(5^{\prime}\right)$. RNA $(2 \mu \mathrm{g})$ was reverse-transcribed with the First-Strand cDNA Synthesis Kit (GE Healthcare, Velizy-Villacoublay, France) according to the manufacturer's 

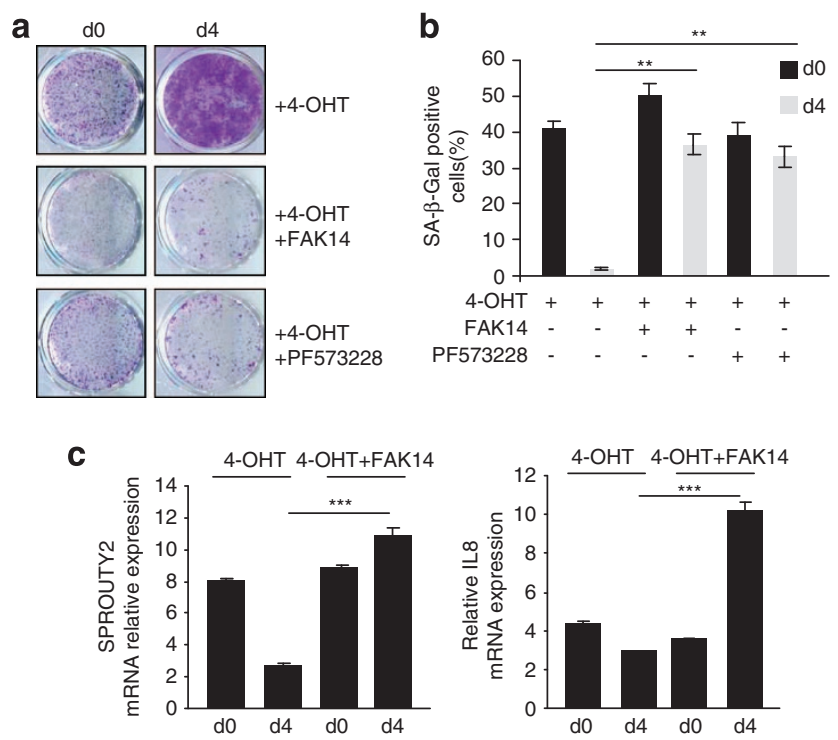

d

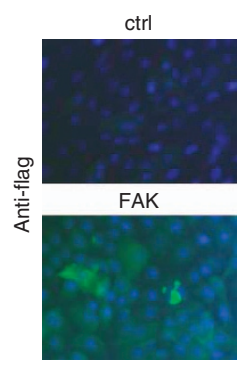

e
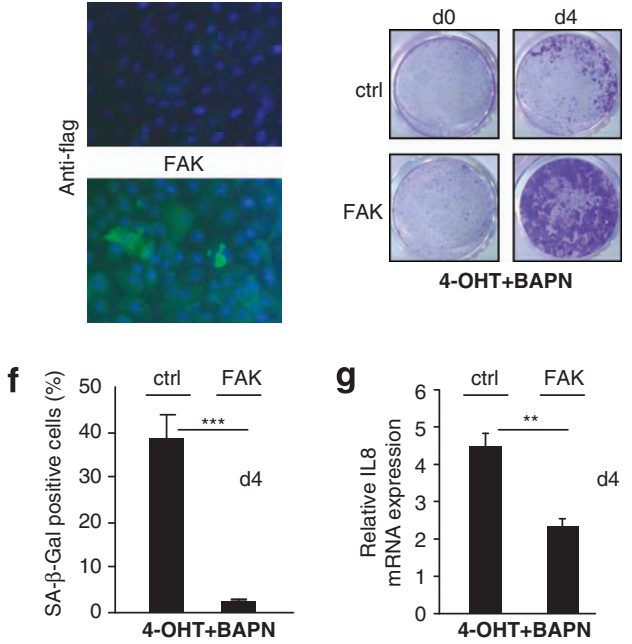

Figure 8 FAK activity participates in senescence modulation by LOX activity. (a) HEC-TM cells were treated with 4-OHT, with or without FAK inhibitors, for 3 days and then cultured for an additional 4 days with or without the indicated FAK inhibitors (d4), fixed, and crystal violet-stained. (b) Cells were fixed and their SA- $\beta$ Gal activity assayed on do and d4. (c) RNA was prepared and RT-qPCR was performed against senescence markers. (d) HEC-TR cells were infected with a FAK-encoding or an empty control retroviral vector and neomycin-selected. Immunofluorescence against the Flag tag was performed. (e) Selected cells were treated with $4-\mathrm{OHT}+\mathrm{BAPN}$ for 3 days (d0) and with BAPN for 4 additional days (d4). Cells were next fixed, crystal violet-stained, and (f) assayed for SA- $\beta$-Gal activity, or (g) RNAs were prepared and RT-qPCR performed on a senescence marker

directions. Q-PCR experiments were carried out in a Light Cycler 2.0 instrument, in Light Cycler Taqman Master Mix (Roche, Meylan, France) and with the Universal Probe Library (Roche Diagnostics, Meylan, France). The following primers were used: IL-8 5'-AGACAGCAGAGCACACAAGC-3' and $5^{\prime}$-ATGGTTCCTTCC GGTGGT-3', SPROUTY2 5'-TTTGCACATCGCAGAAAGAA-3' and $5^{\prime}$-TCA GGTCTTGGAAGTGTGGTC-3', LOX 5'-GGATACGGCACTGGCTACTT-3' and 5'-GACGCCTGGATGTAGTAGGG-3', LOXL1 5'-GCATGCACCTCTCATACCC-3' and 5'-CAGTCGATGTCCGCATTGTA-3', LOXL2 5'-TGACCTGCTGAACCT CAATG- $3^{\prime}$ and $5^{\prime}$-TGGCACACTCGTAATTCTTCTG- $3^{\prime}$. The actin gene was used as a normalizer, with the $5^{\prime}$-ATTGGCAATGAGCGGTTC- $3^{\prime}$ and $5^{\prime}$-GGATGCCAC AGGACTCCAT- $3^{\prime}$ primers.
Mouse engineering and treatment. By crossing Pdx1-Cre; Ink4a/Arf ${ }^{\text {loxlox }}$ (no phenotype) with LSL-Kras ${ }^{\mathrm{G} 12 \mathrm{D} /+}$; Ink4a/Arflox/lox (no phenotype) individuals, we 'routinely' generate Pdx1-Cre;LSL-Kras ${ }^{\mathrm{G} 12 \mathrm{D} /+}$; Ink4a/Arf ${ }^{\text {loxlox }}$ animals (representing $25 \%$ of the total progeny according to the expected Mendelian inheritance) developing macroscopic pancreatic cancer at the frequency of $100 \%$ by the age of $6-7$ weeks. Mice were treated by intraperitoneal injection of BAPN $(100 \mathrm{mg} / \mathrm{kg}$, dissolved in saline) or vehicle three times a week (half) or every day (half). Conditioned cell media from ctrl, LOX-expressing, or LOXL2-expressing cells were concentrated as described, and $100 \mu \mathrm{l}$ of either ctrl supernatant or of a mix of $50 \mu \mathrm{l}$ LOX supernatant and $50 \mu \mathrm{l}$ LOXL2 supernatant was injected intraperitoneally every day for the indicated time. The experiments were performed in accordance with the animal care guidelines of the European Union and French laws and were validated by the local Animal Ethic Evaluation Committee (CECCAPP).

SA-B-Gal analysis. Senescence-associated $\beta$-galactosidase activity was assayed in HECs and on pancreatic sections fixed and stained with the Senescence Beta-galactosidase Kit (Cell Signaling) as recommended by the manufacturer.

Histology and sirius red staining. Pancreatic sections $(4-5 \mu \mathrm{m})$ were stained with HPS. For immunohistochemical analysis, paraffin-embedded murine pancreatic tumor tissues were used. Slides were serially sectioned at $4-\mu \mathrm{m}$ thickness. After deparaffinization and rehydration, the slides were incubated in $5 \%$ hydrogen peroxide in sterile water to block endogenous peroxidases. For heatinduced antigen retrieval, tissue sections were boiled in $10 \mathrm{mmol} / \mathrm{l}$ citrate buffer pH6 in a microwave oven for $20 \mathrm{~min}$. The slides were then incubated at room temperature for 1 hour with the primary antibody diluted in 'low-background' antibody diluent (DAKO Real). After rinsing in PBS, the slides were incubated with a biotinylated secondary antibody bound to a streptavidin peroxidase conjugate (Dako E0468) for 1 hour at room temperature. Bound antibody was revealed and sections were finally counterstained with hematoxylin.

Paraffin-treated sections of pancreas were stained for 1 hour in $0.1 \%$ picrosirius red solution (Direct Red 80, 365548, Sigma) in picric acid solution (P6744, Sigma), washed twice with acidified water, and then mounted in Eukitt quick-hardening mounting medium (03989, Sigma). Samples were analyzed upon polarized light microscopy.

Statistical analysis. The values are presented as mean \pm S.D. unless stated otherwise. Statistical analysis were performed using the Student's $t$-test $\left({ }^{\star} P<0.05,{ }^{* *}<0.01,{ }^{* * *}<0.001\right)$. The number of independent replicates for each experiment was indicated in the figure legends. Survival of the mice was analyzed using a Kaplan-Meier method. P-values were calculated using a log-rank test.

\section{Conflict of Interest}

The authors declare no conflict of interest.

Acknowledgements. We thank members of the laboratory I Puisieux and P Sommer for helpful discussions, and we also thank S Léon, B Kaniewski, S Martel, and M Ferrand for technical assistance. This work was carried out with the support of the 'RTRS Fondation Synergie Lyon Cancer', the 'Association pour la Recherche sur le Cancer', the 'Fondation de France', and the 'Institut National du Cancer'.

1. Serrano M, Lin AW, McCurrach ME, Beach D, Lowe SW. Oncogenic ras provokes premature cell senescence associated with accumulation of p53 and p16INK4a. Cell 1997; 88: 593-602.

2. Chen Z, Trotman LC, Shaffer D, Lin HK, Dotan ZA, Niki M et al. Crucial role of p53dependent cellular senescence in suppression of Pten-deficient tumorigenesis. Nature 2005; 436: 725-730.

3. Collado M, Gil J, Efeyan A, Guerra C, Schuhmacher AJ, Barradas M et al. Tumour biology: Senescence in premalignant tumours. Nature 2005; 436: 642.

4. Michaloglou C, Vredeveld LC, Soengas MS, Denoyelle C, Kuilman T, van der Horst CM et al. BRAFE600-associated senescence-like cell cycle arrest of human naevi. Nature 2005; 436: 720-724.

5. Acosta JC, O'Loghlen A, Banito A, Guijarro MV, Augert A, Raguz S et al. Chemokine Signaling via the CXCR2 Receptor Reinforces Senescence. Cell 2008; 133: 1006-1018.

6. Kuilman T, Michaloglou C, Vredeveld LCW, Douma S, van Doorn R, Desmet CJ et al. Oncogene-induced senescence relayed by an interleukin-dependent inflammatory network. Cell 2008; 133: 1019-1031. 
7. Sun P, Yoshizuka N, New L, Moser BA, Li Y, Liao R et al. PRAK is essential for ras-induced senescence and tumor suppression. Cell 2007; 128: 295-308.

8. Wajapeyee N, Serra RW, Zhu X, Mahalingam M, Green MR. Oncogenic BRAF induces senescence and apoptosis through pathways mediated by the secreted protein IGFBP7. Cell 2008; 132: 363-374.

9. Christoffersen NR, Shalgi R, Frankel LB, Leucci E, Lees M, Klausen M et al. p53independent upregulation of miR-34a during oncogene-induced senescence represses MYC. Cell Death Differ 2010; 17: 236-245.

10. Ewald JA, Desotelle JA, Wilding G, Jarrard DF. Therapy-induced senescence in cancer J Natl Cancer Inst 2010; 102: 1536-1546.

11. Humbert N, Navaratnam N, Augert A, Da Costa M, Martien S, Wang J et al. Regulation of ploidy and senescence by the AMPK-related kinase NUAK1. EMBO J 2010; 29: 376-386.

12. Lin HK, Chen Z, Wang G, Nardella C, Lee SW, Chan CH et al. Skp2 targeting suppresses tumorigenesis by Arf-p53-independent cellular senescence. Nature 2010; 464: 374-379.

13. Scurr LL, Pupo GM, Becker TM, Lai K, Schrama D, Haferkamp S et al. IGFBP7 is not required for B-RAF-induced melanocyte senescence. Cell 2010; 141: 717-727

14. Cipriano R, Kan CE, Graham J, Danielpour D, Stampfer M, Jackson MW. TGF-beta signaling engages an ATM-CHK2-p53-independent RAS-induced senescence and prevents malignant transformation in human mammary epithelial cells. Proc Natl Acad Sci USA 2011; 10: 8668-8673.

15. Bianchi-Smiraglia A, Nikiforov MA. Controversial aspects of oncogene-induced senescence. Cell Cycle 2012; 11: 4147-4151.

16. Kiyono T, Foster SA, Koop J, McDougall JK, Galloway DA, Klingelhutz AJ. Both Rb/ p16INK4a inactivation and telomerase activity are required to immortalize human epithelia cells. Nature 1998; 396: 84-88.

17. Csiszar K. Lysyl oxidases: a novel multifunctional amine oxidase family. Prog Nucleic Acid Res Mol Biol 2001; 70: 1-32.

18. Lucero HA, Kagan HM. Lysyl oxidase: an oxidative enzyme and effector of cell function. Cell Mol Life Sci 2006; 63: 2304-2316.

19. Baker AM, Bird D, Lang G, Cox TR, Erler JT. Lysyl oxidase enzymatic function increases stiffness to drive colorectal cancer progression through FAK. Oncogene 2013; 32 : 1863-1868

20. Barker HE, Chang J, Cox TR, Lang G, Bird D, Nicolau M et al. LOXL2-mediated matrix remodeling in metastasis and mammary gland involution. Cancer Res 2011; 71: $1561-1572$.

21. Herranz N, Dave N, Millanes-Romero A, Morey L, Diaz VM, Lorenz-Fonfria V et al. Lysyl oxidase-like 2 deaminates lysine 4 in histone H3. Mol Cell 2012; 46: 369-376.

22. Peinado H, Del Carmen Iglesias-de la Cruz M, Olmeda D, Csiszar K, Fong KS, Vega S et al. A molecular role for lysyl oxidase-like 2 enzyme in snail regulation and tumor progression. EMBO J 2005; 24: 3446-3458.

23. Vadasz Z, Kessler O, Akiri G, Gengrinovitch S, Kagan HM, Baruch Y et al. Abnorma deposition of collagen around hepatocytes in Wilson's disease is associated with hepatocyte specific expression of lysyl oxidase and lysyl oxidase like protein-2. J Hepatol 2005; 43: 499-507.

24. Erler JT, Bennewith KL, Nicolau M, Dornhofer N, Kong C, Le QT et al. Lysyl oxidase is essential for hypoxia-induced metastasis. Nature 2006; 440: 1222-1226.

25. Erler JT, Bennewith KL, Cox TR, Lang G, Bird D, Koong A et al. Hypoxia-induced lysy oxidase is a critical mediator of bone marrow cell recruitment to form the premetastatic niche. Cancer Cell 2009; 15: 35-44.

26. Bondareva A, Downey CM, Ayres F, Liu W, Boyd SK, Hallgrimsson B et al. The lysyl oxidase inhibitor, beta-aminopropionitrile, diminishes the metastatic colonization potential of circulating breast cancer cells. PLoS One 2009; 4: e5620.

27. Baker AM, Cox TR, Bird D, Lang G, Murray GI, Sun XF et al. The role of lysyl oxidase in SRC-dependent proliferation and metastasis of colorectal cancer. J Natl Cancer Inst 2011; 103: 407-424.

28. Barry-Hamilton V, Spangler R, Marshall D, McCauley S, Rodriguez HM, Oyasu M et al. Allosteric inhibition of lysyl oxidase-like-2 impedes the development of a pathologic microenvironment. Nat Med 2010; 16: 1009-1017.

29. Pez F, Dayan F, Durivault J, Kaniewski B, Aimond G, Le Provost GS et al. The HIF-1inducible lysyl oxidase activates HIF-1 via the Akt pathway in a positive regulation loop and synergizes with HIF-1 in promoting tumor cell growth. Cancer Res 2011; 71: 1647-1657.

30. Lee GH, Kim DS, Chung MJ, Chae SW, Kim HR, Chae HJ et al. Lysyl oxidase-like-1 enhances lung metastasis when lactate accumulation and monocarboxylate transporter expression are involved. Oncol Lett 2011; 2: 831-838.
31. Levental KR, Yu H, Kass L, Lakins JN, Egeblad M, Erler JT et al. Matrix crosslinking forces tumor progression by enhancing integrin signaling. Cell 2009; 139: 891-906.

32. Payne SL, Fogelgren B, Hess AR, Seftor EA, Wiley EL, Fong SF et al. Lysyl oxidase regulates breast cancer cell migration and adhesion through a hydrogen peroxidemediated mechanism. Cancer Res 2005; 65: 11429-11436.

33. Peng L, Ran YL, Hu H, Yu L, Liu Q, Zhou Z et al. Secreted LOXL2 is a novel therapeutic target that promotes gastric cancer metastasis via the Src/FAK pathway. Carcinogenesis 2009; 30: 1660-1669.

34. Trost TM, Lausch EU, Fees SA, Schmitt S, Enklaar T, Reutzel D et al. Premature senescence is a primary fail-safe mechanism of ERBB2-driven tumorigenesis in breast carcinoma cells. Cancer Res 2005; 65: 840-849.

35. Beausejour CM, Krtolica A, Galimi F, Narita M, Lowe SW, Yaswen P et al. Reversal of human cellular senescence: roles of the p53 and p16 pathways. EMBO J 2003; 22: 4212-4222.

36. Takahashi A, Ohtani N, Yamakoshi K, lida S, Tahara H, Nakayama K et al. Mitogenic signalling and the p16INK4a-Rb pathway cooperate to enforce irreversible cellular senescence. Nat Cell Biol 2006; 8: 1291-1297.

37. Courtois-Cox S, Genther Williams SM, Reczek EE, Johnson BW, McGillicuddy LT, Johannessen $\mathrm{CM}$ et al. A negative feedback signaling network underlies oncogeneinduced senescence. Cancer Cell 2006; 10: 459-472.

38. Tang SS, Trackman PC, Kagan HM. Reaction of aortic lysyl oxidase with betaaminopropionitrile. J Biol Chem 1983; 258: 4331-4338.

39. Tang SS, Chichester CO, Kagan HM. Comparative sensitivities of purified preparations of Iysyl oxidase and other amine oxidases to active site-directed enzyme inhibitors. Connect Tissue Res 1989; 19: 93-103.

40. Wilmarth KR, Froines JR. In vitro and in vivo inhibition of lysyl oxidase by aminopropionitriles. J Toxicol Environ Health 1992; 37: 411-423.

41. Welsch T, Kleeff J, Friess $H$. Molecular pathogenesis of pancreatic cancer: advances and challenges. Curr Mol Med 2007; 7: 504-521.

42. Bardeesy N, Sharpless NE, DePinho RA, Merlino G. The genetics of pancreatic adenocarcinoma: a roadmap for a mouse model. Semin Cancer Biol 2001; 11: 201-218.

43. Hingorani SR, Petricoin EF, Maitra A, Rajapakse V, King C, Jacobetz MA et al. Preinvasive and invasive ductal pancreatic cancer and its early detection in the mouse. Cancer Cell 2003; 4: 437-450.

44. Lelievre E, Hinek A, Lupu F, Buquet C, Soncin F, Mattot V. VE-statin/egfl7 regulates vascular elastogenesis by interacting with lysyl oxidases. EMBO J 2008; 27: 1658-1670.

45. Hanks SK, Ryzhova L, Shin NY, Brabek J. Focal adhesion kinase signaling activities and their implications in the control of cell survival and motility. Front Biosci 2003; 8: d982-d996.

46. Kennedy AL, Morton JP, Manoharan I, Nelson DM, Jamieson NB, Pawlikowski JS et al. Activation of the PIK3CA/AKT pathway suppresses senescence induced by an activated RAS oncogene to promote tumorigenesis. Mol Cell 2011; 42: 36-49.

47. Vredeveld LC, Possik PA, Smit MA, MeissI K, Michaloglou C, Horlings HM et al. Abrogation of BRAFV600E-induced senescence by PI3K pathway activation contributes to melanomagenesis. Genes Dev 2012; 26: 1055-1069

48. Boehm JS, Zhao JJ, Yao J, Kim SY, Firestein R, Dunn IF et al. Integrative genomic approaches identify IKBKE as a breast cancer oncogene. Cell 2007; 129: 1065-1079.

49. Counter CM, Hahn WC, Wei W, Caddle SD, Beijersbergen RL, Lansdorp PM et al. Dissociation among in vitro telomerase activity, telomere maintenance, and cellular immortalization. Proc Natl Acad Sci USA 1998; 95: 14723-14728.

50. Woods D, Parry D, Cherwinski H, Bosch E, Lees E, McMahon M. Raf-induced proliferation or cell cycle arrest is determined by the level of Raf activity with arrest mediated by p21Cip1. Mol Cell Biol 1997; 17: 5598-5611.

51. Wang SX, Mure M, Medzihradszky KF, Burlingame AL, Brown DE, Dooley DM et al. A crosslinked cofactor in lysyl oxidase: redox function for amino acid side chains. Science 1996; 273: 1078-1084.

(2) (1) (2) Cell Death and Disease is an open-access journal published by Nature Publishing Group. This work is licensed under a Creative Commons Attribution-NonCommercialShareAlike 3.0 Unported License. To view a copy of this license, visit http://creativecommons.org/licenses/by-nc-sa/3.0/ 